ation of the Committee on Safety of Medicines "in no way absolves the ethical committee from investigating the ethical aspects of that trial".

Patients who are undergoing tests which are not intended for their benefit should be given a full explanation of the proposed procedure and the patient should feel free to withdraw from the tests at any time, says the committee. Except for trivial procedures of which venapuncture is an example, an explanation of the procedure should be given in the presence of a witness.

When the research is intended for the benefit of the patient the committee feels that there are circumstances in which it would be "inappropriate or even inhumane" to give detailed explanations of the procedures involved. Such cases should be investigated with particular care by the appropriate ethical committee.

\section{SOVIET SCIENCE}

\section{Land and Sea}

LUNOKHOD-2, which landed on January 16,1973 , in the Le Monnier crater on the eastern edge of Mare Serenitatis, had a region of particular selenological interest to explore-the transition from mare to highland. Operating among features assigned unofficial working names such as 'Head-on Hills', 'Shallow Crater', 'Round Bay', 'Near Cape', 'Far Cape' and 'Straight Rille', the Lunokhod recorded and transmitted data of considerable significance, not only to the interpretation of this specific type of area but to lunar research as a whole.

One of the most important experiments of Lunokhod-2 was the determination of possible changes in chemical composition of the transition area surface. A modified version of the RIFMA X-ray spectrograph used on Lunokhod-1 was used-the new instrument, RIFMA-M, being specifically adapted to determining the ratio of iron to other elements -notably aluminium and titanium. Near the landing site, on the slope of a crater of diameter $40 \mathrm{~m}$, readings of $\mathrm{Si}, 24 \pm 4 \% ; \mathrm{Ca}, 8 \pm 1 \%$; $\mathrm{Fe}, 6 \pm 0.6 \%$; and $\mathrm{Al}, 9 \pm 1 \%$ were obtained. (The iron reading obtained by Lunokhod-1 for Mare Imbrium was 10 to $12 \%$.) As Lunokhod-2 moved southwards, towards the 'Head-on Hills' on the edge of the highland, no significant changes were at first observed-data from a $13 \mathrm{~m}$ diameter crater at approximately $1.5 \mathrm{~km}$ from the landing site were close to the first readings. But as it moved closer to the hills the iron content.decreased and $5 \mathrm{~km}$ from the landing site it had fallen to $4.9 \pm 4 \%$. On February 19 a minimum reading of $4.0 \pm 0.4 \%$ was obtained. During this part of the survey, the aluminium content increased to $11.5 \pm 1.0 \%$. Writing in Pravda (November 20, 1973), Academician A. Vinogradov and Dr S. Solokhov attribute this change to a general variation in regolith composition in mare-to-highland transitions.

Panoramic television surveying of the transitional region revealed a number of interesting features, including a crater of diameter 15 to $20 \mathrm{~m}$ in the neighbourhood of the 'Head-on Hills' with associated slip terraces of some 10 to $15 \mathrm{~m}$. In this region the density of small craters (diameter 2 to $3 \mathrm{~m}$ ) fell to one half to one third of the average maria density.

A particular object of investigation was the 'Straight Rille', which stretches for some 15 to $16 \mathrm{~km}$ in a north-south direction along the south-east edge of Le Monnier. On both the eastern and western edges of the rille, a 30 to $40 \mathrm{~m}$ zone of intensive shear towards the fault was observed. The thickness of the regolith decreased as the lunokhod approached the rille and the lip consisted of a rock 'border' with boulders of diameter at least 1 to $2 \mathrm{~m}$.

One interesting feature of the Lunokhod-2 programme was an attempt to correlate chemical composition to visual observation of the albedo. Using photometic telephotography from Earth and the RIFMA-M observations, a general relationship between the readings has been established. This is a result which is considered by the Soviet team to "extend considerably the significance of the Lunokhod-2 results".

The magnetometer experiments, a new feature of Lunokhod-2, revealed some characteristic variations in the field attributed to induction currents produced by variations in the interplanetary field. These data, it is claimed, should reveal the conductivity of the Moon to a depth of some hundreds of kilometres.

\section{NUCLEAR WEAPONS \\ Poor Security}

by our Washington Correspondent

LAST month, when fighting in the Middle East ras at its peak, the United States Atomic Energy Commission (AEC) ordered security to be stepped up at all institutions which handle enriched uranium and plutonium, to ensure that none of the material could be stolen and end up as part of a nuclear finale to the Arab-Israeli conflict. The extra precautions were, it seems, more than justified, for a recent investigation by the General Accounting Office (GAO) has come up with the disturbing finding that security arrangements in some plants which hold strategic nuclear materials would pose few problems for a hamfisted amateur burglar, let alone a terrorist organisation.

The most expensive, lengthy and diffi- cult part of making a nuclear weapon is the production of fissionable material, but fabrication of the weapon itself is reckoned to be a relatively easy task which would not be beyond the wit of scientists in most countries. Thus, if a supply of enriched uranium or plutonium could be diverted from installations in the United States, probably over a period of time, nuclear weapons could be within reach of those willing to pay the price. A crude bomb, such as the ones dropped on Hiroshima or Nagasaki, would require some $17 \mathrm{~kg}$ of enriched uranium or about $6 \mathrm{~kg}$ of plutonium, and it would, of course, take only one such bomb-or the threat of it - to upset the military balance in the Middle East.

The AEC itself acknowledged such risks in an internal report in 1971, which came to the conclusion that "as long as significant quantities of nuclear materials are in active use by the government, by government contractors, and by licensed commercial and other interests, there will be a distinct probability that some of those materials will be stolen, unexplainably or accidentally lost, diverted from authorised use, or used or disposed of in unauthorised ways".

With such considerations in mind the GAO, which carries out investigations for Congress, inspected the security arrangements in three plants which hold strategically important quantities of special nuclear material (as enriched uranium and plutonium are called). It found that in two of the plants, security "was so limited that protection was inadequate".

This is what the GAO found at one of the plants which, mercifully, remained nameless. The plant was protected by a part-time security officer and four armed guards, one of whom was on duty at all times, and it was surrounded by an 8 -foot high wire fence. Special nuclear material, some of which is described in the report as being "of high strategic importance", was located in three buildings just inside the fence. Entrances to the building were connected to an alarm system.

On the face of things, that seems a fairly good security system, but the GAO found that it had the following defects :

- The fence had thirteen weaknesses, ranging from broken welds to inoperative locks, which would allow it to be breached with ease. Ten of the weaknesses were out of sight of the guard post.

- One of the storage areas was a prefabricated structure, just 16 foot from the fence, made from sheet steel panels 3 foot by 9 foot. According to the GAO investigators, who tested the strength of the panels with an adjustable spanner, "within 1 minute we were able to remove five metal screws from 
one of the panels. At this point, the only impediment to entry was a small rivet which, in our opinion, could have been forced manually". Moreover, within 30 seconds, the investigators cut a 19-inch section of the panel with tin cutters.

The door to the building could be opened easily because the lock had been broken, and it could be opened without activating the alarm.

- A second storage area could easily be entered through a vent in one of the walls. "With little effort", the GAO report states, "the louvres could be pulled out by hand and the inside screen could be manually forced, providing access to the building interior".

- Once inside the building, an intruder would have little difficulty in obtaining special nuclear material because it was stored in portable containers, which were "readily accessible". Moreover, plant personnel rarely entered the storage areas in the evening and night shifts, and the guards made regular rounds which could easily be monitored.

- Finally, all external means of communication at the plant were handled by a single cable, which entered the facility at a point which the guard could not see from his post. "Severing this cable would eliminate all means of timely conmunication with outside law enforcement agencies", the report notes.

The AEC says that it has taken steps to remedy the specific deficiencies outlined in the GAO report and earlier this year it issued a set of new regulations to tighten security at plants containing special nuclear materials. Nevertheless, the report does little to establish public confidence in the AEC's ability to keep an eye on its contractors and licensees, and it neatly underlines one of the arguments that critics of nuclear power have been persistently raising in the past few years.

It is frequently argued that proliferation of nuclear power plants will lead to an increase in the quantities of enriched uranium and plutonium in the United States, which will greatly increase the problems of ensuring that none of the material gets diverted into dangerous hands. At present, there are some ninety-five facilities in the United States which have at least $5 \mathrm{~kg}$ of weapons-grade nuclear material but by 1980 the AEC estimates that more than 1 million $\mathrm{kg}$ of special nuclear material will be required for the domestic power industry. Moreover, when the fast breeder reactor starts producing electricity in the 1980 s, it will also start producing large quantities of plutonium. The extra precautions taken during the Middle East war will clearly be required on a longer term basis.

\section{Short Notes}

\section{Crisis Under Control}

STOPPING over in a power-reduced London on his way from a powerreduced Washington to a presumably warm Moscow, Dr Guyford Stever, director of the National Science Foundation and Science Adviser to President Nixon, paused long enough to tell a group of shivering journalists at the United States Embassy (where they take these things patriotically and the conference room central heating was down 20 degrees from the previous week) that the United States is going to more than double its expenditure on energy research over the next five years. A few years ago, Dr Stever said, about $\$ 400$ million was spent each year on energy research. This year it was between $\$ 700$ and $\$ 800$ million. Next year it would be $\$ 1,000$ million and over the next five years $\$ 10,000$ million.

Nonetheless, Dr Stever said, there will be a serious energy shortage in the United States for the next five years. The solution, he believes, lies in exploring coal liquefaction and gasification and in energy conservation. Fusion, he said, might be with us by the year 2000 , although the enormous capital investment involved might make its progress slower than some people believe. Solar energy might also be making a contribution by then.

At any rate, the United States is determined as soon as possible to become completely independent of any other country for its energy. The Arabs, Dr Stever added, had precipitated the energy crisis in the United States but it was a problem that was coming anyway.

As for nuclear reactor safety, proper engineering and design can "easily handle" the problems. There is always a small danger, he said, but then no member of the public has ever been killed or seriously injured by an atomic accident in the United States.

\section{Critical Difference}

A now is brewing in the United States over just how severe the energy crisis is likely to be this winter. According to President Nixon and other Administration spokesmen, supplies of oil will be between 10 and $17 \%$ short of demand when averaged out across the country and the crisis, although severe, will not result in undue hardship. But according to a study carried out by the Library of Congress and published last week in the Congressional Record, the shortfall could reach a staggering $35 \%$ if the weather turns out to be unduly cold and if there is no relaxation of the Arab oil embargo. Moreover, even if the winter is relatively mild and Middle East oil starts flowing again soon, the
Library of Congress reckons that the gap between supply and demand will still be $20 \%$.

The chief difference between the forecasts is that the Administration's sanguine predictions would probably not require rationing of petrol and heating oil, whereas the more pessimistic predictions of the Library of Congress almost certainly would. The disagreement is not, however, restricted to a battle of words between members of Congress and the Administration, for some of the President's own advisers are unhappy about the effects on public opinion if the Administration's reassurances turn out to be without foundation.

\section{Australian Research}

THE annual report of the Commonwealth Scientific and Industrial Research Organisation (CSIRO) of Australia for the year ending June 30, 1973, reveals that the total expenditure of the organisation increased by $\$ A 6.17$ million to \$A73.7 million during the year.

The report states that CSIRO is at present undergoing a significant reorientation. In the past it has been "industry oriented" but it is now striving to become "people oriented". To achieve this aim the organisation is, for example, changing the tone of its environmental research so that its relevance to industry is "more tenuous".

With this change of emphasis the report states that there is a need for a more effective communication "with the community as a whole". The organisation is taking steps to meet these needs but gives no details of the procedures involved.

\section{Nixon's Economy}

Soon after exhorting all Americans to conserve energy to help stave off a potential crisis this winter, President Nixon boarded his presidential airliner for a weekend trip to Florida. According to the White House, the return journey used up 8,000 gallons of fuel. According to the Washington Post, which is not one of Mr Nixon's most ardent admirers, that amount of fuel would have allowed one commuter to travel from the outskirts of Washington to his office and back every day for 11 years. Mr Nixon did, however, order the pilot of his aircraft to slow down to 475 miles an kour, thus saving 200 gallons of fuel an hour.

\section{Mars for $10 p$}

A 'street astronomer' has been spotted in London's Shaftesbury Avenue. Armed with a 75-mm telescope and sky maps, he offers passers-by a view of Mars for $10 \mathrm{p}$ (Junior Astronomical Society Circular, No. 57; November 1973). 